\title{
Bioactivity of Antibacterial Compounds Produced by Endophytic Actinomycetes
}

\section{from Neesia altissima}

\author{
Rina Hidayati Pratiwi ${ }^{1 *}$, Muhammad Hanafi ${ }^{2}$, Nina Artanti ${ }^{2}$, Rosa Dewi Pratiwi ${ }^{1}$ \\ ${ }^{1}$ Department of Biological Education, Universitas Indraprasta PGRI, Jakarta, Indonesia \\ ${ }^{2}$ Research Center for Chemistry, Indonesian Institute of Sciences, Tangerang Selatan, Indonesia
}

\begin{abstract}
Identification of alternate bioactive compounds isolated from microbial endophytes from plants may lead to better solution against antibiotic resistance. Main objective of this research is to determine the bioactivity of antibacterial compounds produced by endophytic actinomycetes, which was isolated from stem bark of Neesia altissima Bl. at Halimun Salak Mount. Detection of bioactive compounds was assayed using Thin Layer Chromatography (TLC) by employing bioautography. Bioactivity was assayed using crude extract against five microorganisms using agar diffusion methods. Tetracycline was used as a positive control. The result of antibacterial activity from endophytic actinomycetes isolate revealed that the bioactive compounds were effective in inhibiting the growth of bacteria Bacillus cereus $(1.25 \mathrm{~mm})$, Salmonella typhimurium $(5.75 \mathrm{~mm})$, and Shigella flexneri $(4.37 \mathrm{~mm})$. Bioactivity of ethyl acetate extract from bioactive compounds of endophytic actinomycetes has an antibacterial activity against bacteria Bacillus cereus $(13.00 \mathrm{~mm})$ and Staphylococcus aureus $(15.90 \mathrm{~mm})$, at a concentration of 250,000 ppm. Each of TLC fraction was able to inhibit growth of $B$. cereus at a minimum concentration of $10,000 \mathrm{ppm}$. In conclusion, the bioactive compounds produced by endophytic actinomycetes can have inhibitory effect towards $B$. cereus. The category of that compounds are narrow spectrum. The bioactive compound isolated from endophytic actinomycetes may have other implications such as anticancer, antifungal, and antioxidant.
\end{abstract}

Keywords: Bioactivity, bioactive compounds, effectivity, Neesia altissima Bl., Streptomyces sp.

\section{INTRODUCTION}

The long-term and extensive use of antibiotics has led to the emergence of a large number of drug resistant strains. According to the reports incidences of Mycobacterium tuberculosis infection have reached up to $10.2 \%$. Pathogenic bacteria such as Mycobacterium tuberculosis and Staphylococcus aureus are susceptible to mutations and are more likely to cause drug resistance [1]. The increasing incidence of drug resistance in pathogenic bacterial, fungal infections and certain cancers has prompted a search for more and better agents [2]. Actinomycetes is the main source of antibiotics and endophytic actinomycetes isolated from medicinal plants has considerable development potential. Neesia altissima $\mathrm{Bl}$. (Bengang) is one of medicinal plants that have

${ }^{*}$ Corresponding author:

Rina Hidayati Pratiwi

Department of Biological Education, Universitas Indraprasta PGRI

Jalan Nangka 58 C (TB. Simatupang), Jakarta, Indonesia 12530

E mail: rina.hp2012@gmail.com been used for centuries as remedies for diarrhea, disuria, and gonorrhoea diseases at around west Java, Indonesia. Kudo et al. (1998) [3]; Chen et al. (2009) [4]; Qin et al. (2008 [5], 2010 [6]) have found a few actinomycetes from tissue of medicinal plants constantly from the present findings. Moreover, most endophytic actinomycetes of medicinal plants can produce important compounds and some of them have new chemical structure [7, 8, 9]. Igarashi et al. (2002) [10] isolated 398 actinomycete strains from leaves, stems and roots of cultivated and wild plants that showed antagonistic activity against phytopathogenic fungi and bacteria at $10-20 \%$ of the $\mathrm{n}$-butanol extracts of their fermentation broths. Igarashi et al. (2000) [11] reported that a wide range of endo-

\footnotetext{
How to cite:

Pratiwi RH, Hanafi M, Artanti N, Pratiwi RD (2018) Bioactivity of Antibacterial Compounds Produced by Endophytic Actinomycetes from Neesia altissima. J. Trop. Life. Science 8 (1): $37-42$.
} 
phytic actinomycetes have a potential to produce antimicrobial compounds. Sasaki et al. (2001a, 2001b) [12, 13] identified several new bioactive compounds produced by actinomycetes isolated from live plants. Two new novobiocin analogs produced by Streptomyces sp. collected of Aucuba japonica [12] and cedarmycins by Streptomyces sp. collected from Cryptomeria japonica [13] were determined to be antimicrobial metabolites. A new naphthoquinone antibiotic, alnumycin, was also reported in Streptomyces sp. isolated from root nodules of Alnus glutinosa collected in Germany [14]. Shimizu et al. (2004) [15] proved that Streptomyces galbus strain $\mathrm{R}-5$ produced actinomycin X2 and fungichromin that could account for the in vitro anti-bacterial and anti-fungal activities.

The development and improvement of accurate and efficient methods for rapid antibiotic susceptibility testing is important for public health. Antimicrobial susceptibility information about pathogens may significantly reduce morbidity and mortality, cost of treatment, and duration of hospitalization if this information can be provided to clinicians in a rapid and timely fashion [16]. The aim of this study was to investigate the bioactivity of antibacterial bioactive compounds isolated from endophytic actinomycetes $N$. altissima.

\section{MATERIALS AND METHODS Isolation of the compounds}

For the preparation of crude extract samples of endophytic Actinomycetes were soaked twice with ethyl acetate for 24 hours. The extract was evaporated under reduced pressure and at a temperature of $35^{\circ} \mathrm{C}$ until total evaporation of the ethyl acetate.

\section{Determination of antimicrobial activities}

For the antimicrobial testing, a crude extract of the ethyl acetate was prepared in pure dimethylsulfoxide (DMSO) at 250,000; 50,000; 10,000; 5,000; 1,000; and $100 \mathrm{ppm}$. Streptomyces sp. strain UICC B-92 was isolated from Neesia altissima and kept on International Streptomyces Project (ISP)2 medium. The isolate have stored at Universitas Indonesia Culture Collection (UICC), UI Depok. Overnight broth cultures, adjusted to yield approximately $10^{8} \mathrm{cfu} / \mathrm{mL}$ for bacteria were streaked with a calibrated loop on plates containing appropriate solid medium. Filter paper discs (6 mm diameter; Oxoid) were placed on the inoculated agar surfaces and impregnated with $15 \mathrm{~mL}$ of stock solutions. Pure DMSO $(15 \mathrm{~mL})$ was used as a negative control while tetracycline discs $(100 \mathrm{mg})$ were used as positive controls. The plates were observed after 18 hours at $37^{\circ} \mathrm{C}$. All tests were performed in duplicate and the antibacterial activity was expressed as the mean of inhibition diameters $(\mathrm{mm})$ produced by the crude extracts of endophytic Actinomycetes.

\section{Extraction for production of secondary metabolite}

An established slant of isolate was inoculated in a $250 \mathrm{~mL}$ flask containing $50 \mathrm{~mL}$ of vegetative medium (ISP2 medium) consisting of yeast extract $4 \mathrm{~g} / \mathrm{L}$, malt extract $10 \mathrm{~g} / \mathrm{L}$, dekstrosa $4 \mathrm{~g} / \mathrm{L}$, and demineral water 50 $\mathrm{ml}$. The flask was incubated at $30^{\circ} \mathrm{C}$ for 2 days in an incubator-shaker. Fifty milliliters of the culture was transferred to $1,000 \mathrm{~mL}$ of the fermentation medium. The fermentation medium consisted of glucose $4 \mathrm{~g} / \mathrm{L}$, bacto peptone $15 \mathrm{~g} / \mathrm{L}$, yeast extract $3 \mathrm{~g} / \mathrm{L}, \mathrm{Fe}$ (III) citrate hydrate $0.3 \mathrm{~g} / \mathrm{L}$, and dematerialized water $1000 \mathrm{~mL}$ [17]. The fermentation was carried out at $30^{\circ} \mathrm{C}$ for 5 days in an incubator-shaker.

The residue was suspended in water and extracted successively three times with hexane, chloroform, ethyl acetate and methanol. The $\mathrm{n}$-methanolic extract was then separated on a column chromatography using silica gel 60 G F254 [18].

\section{Detection of antibacterial activity by using bioautography method}

The agar overlay method (immersion bioautography) was used for detection of antibacterial bioactive compounds. TLC plate (Merck Silica Gel 60 F254) was loaded with $10 \mu \mathrm{L}$ of crude extract of endophytic Actinomycetes. The solvent system used was chloroform : methanol $(5: 1)$. The chromatogram was kept for evaporation of the solvent. Developed chromatogram was placed on sterile nutrient agar plate $(15 \mathrm{~mL})$ for detection of antibacterial activity. For detection of antibacterial activity, $5 \mathrm{~mL}$ of nutrient agar was seeded with $1 \mathrm{~mL}$ of spore suspension of Bacillus cereus $\left(0.1 \mathrm{~A} 540=10^{7}\right.$ spores $/ \mathrm{mL}$ ) was poured on chromatogram. After agar got solidified the petri plates were kept at $4^{\circ} \mathrm{C}$ for diffusion for 3 hours. Plates were then incubated at room temperature for 24 hours for bacterial culture. The antimicrobial activity was observed by inhibition zone and the $\mathrm{hRf}$ value was defined.

\section{RESULTS AND DISCUSSION}

The results of the antibacterial activity of endophytic Actinomycetes and ethyl acetate extracts are listed in 
Table 1. Antibacterial activity of endophytic actinomycetes

\begin{tabular}{llllll}
\hline \multirow{2}{*}{ Isolate } & \multicolumn{5}{c}{ Diameter of inhibition zone (mm) } \\
\cline { 2 - 6 } & B. cereus & E. coli & S. aureus & S. typhimurium & S. flexneri \\
\hline UICC B-92 & & & & & \\
K $(+)$ & 1.25 & - & - & 5.75 & 4.37 \\
& 9.00 & 9.00 & 9.00 & 9.00 & 9.00 \\
\hline
\end{tabular}

Note: (-): no inhibition zone; K (+): positive control

Table 2. Antibacterial activity of ethyl acetate extract of bioactive compounds from endophytic actinomycetes

\begin{tabular}{|c|c|c|c|c|}
\hline \multirow{2}{*}{ Treatment } & \multirow{2}{*}{ Concentration (ppm) } & \multicolumn{3}{|c|}{ Diameter of inhibition zone ( $\mathrm{mm})$} \\
\hline & & B. cereus & S. flexneri & S. aureus \\
\hline \multirow{7}{*}{ With shaking } & 50,000 & $7.50 \pm 7.00$ & - & - \\
\hline & 10,000 & $6.50 \pm 7.00$ & - & - \\
\hline & 5,000 & - & - & - \\
\hline & 1,000 & - & - & - \\
\hline & 100 & - & - & - \\
\hline & 250,000 & $13.00 \pm 13.00$ & $8.00 \pm 8.00$ & $7.00 \pm 6.50$ \\
\hline & $\mathrm{K}(+)$ & 9 & 9 & 9 \\
\hline \multirow{7}{*}{ No shaking } & 50,000 & $7.00 \pm 7.00$ & - & - \\
\hline & 10,000 & $7.00 \pm 7.00$ & - & - \\
\hline & 5,000 & - & - & - \\
\hline & 1,000 & - & - & - \\
\hline & 100 & - & - & - \\
\hline & 250,000 & $7.50 \pm 6.50$ & - & $16.50 \pm 15.20$ \\
\hline & $\mathrm{K}(+)$ & 9 & 9 & 9 \\
\hline
\end{tabular}

Note: (-) : no inhibition zone; $\mathrm{K}(+)$ : positive control (tetracycline)

Table 1 and 2, respectively. The bioautography revealed clear zones of bacterial growth inhibition for Bacillus cereus while, for Staphylococcus aureus, zones of inhibition were less visible.

The endophytic actinomycetes have been identified at previously research [19]. They are Streptomyces sp. UICC B-92. The genus Streptomyces is an important group of actinomycetes because of its ability to produce many types of secondary metabolites [20] and approximately two-thirds of all known natural antibiotics are produced by these bacteria. Streptomyces is known to produce antitumour drugs such as the anthracycline antibiotic, daunorubicin, or the bleomycin complex; autoimmune active agents such as the macrolide tacrolimus; antimicrobial compounds like phenazines [21]. Antibacterial activity of endophytic actinomycetes isolate, Streptomyces sp. UICC B-92 have inhibited the growth of Bacilus cereus, Salmonella typhimurium and Shigella flexneri (Table 1). That result is different from crude extract of compounds (Table 2). The reason of this difference may be due to the fact that target compounds have not been isolated yet. One or more components could be separated from a mixture by the extraction process.

In the fermentation process, yield more was produced from Streptomyces sp. UICC B-92 isolate during $5-7$ days incubation. That bioactive compounds of endophytic actinomycetes showed high in vitro antibacterial activity against $B$. cereus ATCC 10876 and $S$. aureus ATCC 25923 but not against Gram negative bacteria. The crude extract from the endophytic Actinomycetes isolate showed that the isolate of UICC B-92 have antibacterial activity against $B$. cereus more than $S$. aureus and another test bacteria (Table 2). The standard devia- 


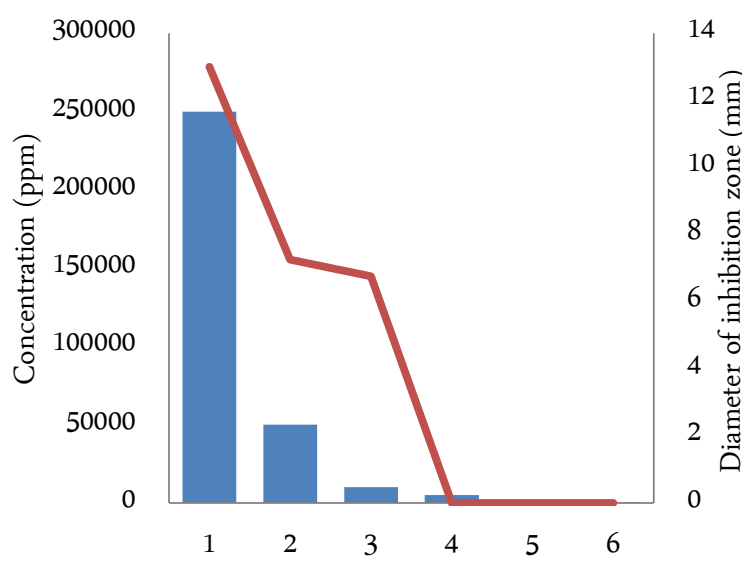

Figure 1. Antibacterial activity for B. cereus

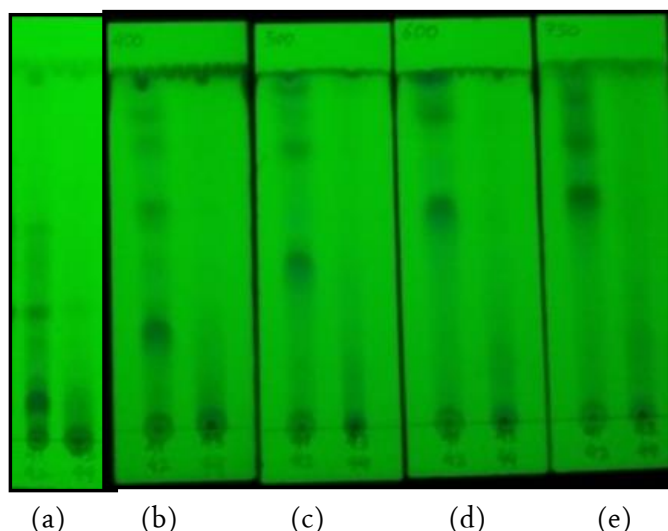

Figure 2. TLC of endophytic actinomycetes (fraction $41-42$ ) before purification with chloroform $(\mu \mathrm{L})$ : methanol $(\mu \mathrm{L})=2000: 250(\mathrm{a}) ; 2000: 400(\mathrm{~b}) ; 2000: 500(\mathrm{c}) ;$ $2000: 600(\mathrm{~d}) ; 2000: 750(\mathrm{e})$

tion of antibacterial activity for $B$. cereus is 0.76 . The value of standard deviation showed homogeneity for the data sample (Figure 1). The higher sensitivity of the gram positive bacteria than gram negative bacteria is possibly due to their differences in cell wall constituents and their arrangement. The outer membrane of gram negative bacteria carrying the structural lipopolysaccharide components is an effective barrier against hydrophobic substances [22, 23], while gram positive bacteria cell wall contain a peptidoglycan layer, which is an ineffective permeability barrier. Based on the result, concentration of $250 \mathrm{ppm}$ showed $6.25 \mathrm{~mm}$ inhibition zone against $B$. cereus. This data suggested that these Actinomycetes endophytes from $N$. altissima provided potential for production of secondary metabolites against the diarrhea-causing bacteria. They indicated promising capability to produce useful bioactive compounds.

The antibacterial activity of an isolate has been de-

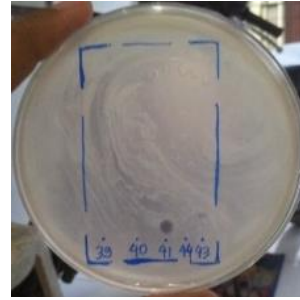

(a)

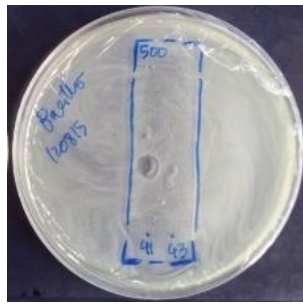

(c)

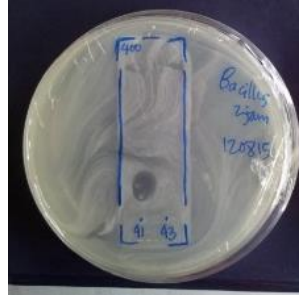

(b)

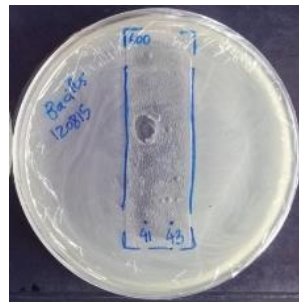

(d)

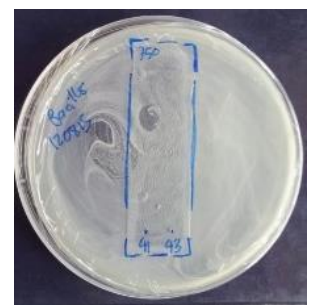

(e)

Figure 3. Bioautography visualisation of antibacterial bioactive compounds from endophytic actinomycetes with chloroform $(\mu \mathrm{L})$ : methanol $(\mu \mathrm{L})=2000: 250(\mathrm{a}) ; 2000: 400$ (b); $2000: 500$ (c); $2000: 600$ (d); $2000: 750$ (e)

tected by various methods like dilution methods (agar diffusion and MIC) and bioautography methods. Bioautography is sensitive method for detection of antimicrobial compounds even in small amounts [24]. Hence for detection of antibacterial compounds, bioautography is suitable method in initial stages as compared to agar dilution methods [25]. Bioautography is a sensitive method and can be directly employed for isolation of active constituents [26]. Bioautography screening methods are based on the biological activities, e.g. antibacterial, antifungal, antitumour, and antiprotozoae of the tested substances [27]. The detection method in this research used thin-layer chromatography (TLC) (Figure 2). The methods have been successful due to combination of layer liquid chromatography techniques. Bioautography visualization of antibacterial bioactive compounds from endo-phytic Actinomycetes (Figure 3) revealed inhibition zone of the spot at $41-42$ fraction on TLC. The result of bioautography shown antibacteria 
activity toward $B$. cereus has valid value of $\operatorname{Rf} 4.66,6.16$, and 7.67 while for the size of inhibition zone has sufficiently wide, $7.25 \mathrm{~mm}$ averaged (Table 3). From that results shown repeatedly the potential of endophytic Actinomycetes for the discovery of novel bioactive compounds, having antibacterial activity. The data of this result suggested that Streptomyces sp. UICC B-92 from $N$. altissima provided potential sources for the discovery of new secondary metabolites to combat the diarrhea causing bacteria.

\section{CONCLUSION}

Bioautogram showed that $\mathrm{Rf}$ value of spot derived from the bioactive compounds isolated from Streptomyces sp. strain UICC B-92 are 4.66, 6.16, and 7.67, which have significant for the average of inhibition zone is 7.25 $\mathrm{mm}$. It was found that the crude extract of bioactive compounds from endophytic actinomycetes has an antibacterial activity for controlling Gram positive bacteria, especially B. cereus ATCC 10876.

\section{ACKNOWLEDGMENT}

This research was supported by Research Grant of Hiber DIKTI 2016 and PPT DIKTI 2017 awarded to RHP number 0581/K3/KM/2016 and number 28/E/KPT/2017 respectively. We would like to thank to LPPM Staff of Universitas Indraprasta PGRI and Chemistry Laboratory at Research Center for Chemistry, Indonesian Institute of Sciences (LIPI), PUSPIPTEK, Serpong for valuable technical assistance.

\section{REFERENCES}

1. Monaghan RL, Barrett JF (2006) Antibacterial drug discovery-then, now and the genomics future. Biochemical Pharmacology 71 (7): 901 - 909. doi: 10.1016/j.bcp.2005.11.023.

2. Strobel GA, Daisy B (2003) Bioprospecting for microbial endophytes and their natural products. Microbiology Molecular Biology Reviews 67 (4): 491 - 502. doi: 10.1128/MMBR.67.4.491-502.2003.

3. Kudo T, Matsushima K, Itoh T et al. (1998) Description of four new species of the genus Kineosporia: Kineosporia succinea sp. nov, Kineosporia milkurie sp.nov. and Kineosporia rhamnosa sp. nov., isolated from plant samples and amended description the genus Kineosporia. International Journal of Systematic Bacteriology 48 (4): 1245 - 1255. doi: 10.1099/00207713-48-4-1245.

4. Chen HH, Qin S, Li J (2009) Pseudonocardia endophytica sp. nov., isolated from the pharmaceutical plant Lobelia clavata. International Journal of Systematic Evolutionary Microbiology 59 (3): 559 - 563. doi: 10.1099/ijs.0.64740-0.
5. Qin S, Wang HB, Chen HH (2008) Glycomyces endophyticus sp. nov., an endophytic actinomycete isolated from the root of Carex baccans Nees. International Journal of Systematic Evolutionary Microbiology 58 (11): 2525 - 2528. doi: 10.1099/ijs.0.2008/000398-0.

6. Qin S, Chen HH, Klenk HP (2010) Saccharopolyspora gloriosae sp. nov., an endophytic actinomycete isolated from the stem of Gloriosa superba L. International Journal of Systematic Evolutionary Microbiology 60 (5): 1147 - 1151. doi: 10.1099/ijs.0.015792-0.

7. Caruso M, Colombo AL, Crespi PN (2000) Studies on a strain of Kitasatospora sp. paclitaxol producer. Annals of Microbiology 50: $89-102$.

8. Ezra D, Castillo UF, Strobel GA (2004) Coronamycins, peptide antibiotic sproduced by a verticillate Streptomyces sp. (MSU-2110) endophytic on Monstera sp. Microbiology 150 (4): 785 - 793. doi: 10.1099/mic.0.26645-0.

9. Liu N, Zhang H, Zheng W (2007) Bioactivity of endophytic from medicinal plants and secondary metabolites from strain D62. Acta Microbiologica Sinica 47 (5): 823 - 827.

10. Igarashi Y, Iida T, Sasaki Y et al. (2002) Isolation of actinomycetes from live plants and evaluation of antiphytopathogenic activity of their metabolites. Actinomycetologica 16 (1): 9 - 13. doi: 10.3209/saj.16_9.

11. Igarashi Y, Ogawa M, Sato Y et al. (2000) Fistupyrone, a novel inhibitor of the infection of Chinese cabbage by Alternaria brassicicola, from Streptomyces sp. TP-A0659. Journal of Antibiotics 53 (10): 1117 - 1122. doi: 10.7164/antibiotics.53.1117.

12. Sasaki T, Igarashi Y, Saito N, Furumai T (2001) TPU-0031$\mathrm{A}$ and $\mathrm{B}$, new antibiotics of the novobiocin group produced by Streptomyces sp. TP-A0556. Journal of Antibiotics 54 (5): 441 - 447. doi: 10.7164/antibiotics.54.441.

13. Sasaki T, Igarashi Y, Saito N, Furumai T (2001) Cedarmycins $\mathrm{A}$ and $\mathrm{B}$, new antimicrobial antibiotics from Streptomyces sp. TPA0456. Journal of Antibiotics 54 (7): 567 - 572. doi: 10.7164/antibiotics.54.567.

14. Bieber B, Nuske J, Ritzau M, Grafe U (1998) Alnumycin, a new napthoqionone antibiotic, produced by an endophytic Streptomyces sp. Journal of Antibiotics 51 (3): 381 - 382. doi: 10.7164/antibiotics.51.381.

15. Shimizu M, Igarashi $Y$, Furumai $T$ et al. (2004) Identification of endophytic Streptomyces sp. R-5 and analysis of its antimicrobial metabolites. Journal of General Plant Pathology 70 (1): 66 - 68. doi: 10.1007/s10327-003-0082-7.

16. Backes BA, Cavalieri SJ, Rudrik JT, Britt EM (1984) Rapid antimicrobial susceptibility testing of Gram-negative clinical isolates with the AutoMicrobic system. Journal of Clinical Microbiology 19 (6): 744 - 747 . 
17. Nedialkova D, Mariana N (2005) Screening the antimicrobial activity of Actinomycetes strains isolated from Antarctica. Journal of Culture Collections 4: $29-35$.

18. Han L, Ji L, Boakye-Yiadom M et al. (2012) Preparative isolation and purification of four compounds from Cistanches deserticola Y.C. Ma by High-Speed Counter-Current Chromatography. Molecules 17 (7): 8276 - 8284. doi 10.3390/molecules17078276.

19. Pratiwi RH, Hidayat I, Hanafi M, Mangunwardoyo W (2017) Identification and screening of rare actinomycetes isolated from Neesia altissima Bl. In Proceeding of AIP Conference. doi: 10.1063/1.4991203.

20. Olano C, Mendaz C, Salar JA (2009) Antitumor compounds from marine actinomycetes. Marine Drugs 7 (2): 210 - 248. doi: $10.3390 / \mathrm{md} 7020210$.

21. Le Goff G, Martin MT, Servy C et al. (2012) Isolation and characterization of $\alpha, \beta$-unsaturated $\gamma$-lactono-hydrazides from Streptomyces sp. Journal of. Natural Products 75 (5): 915 - 919. doi: 10.1021/np300026p.

22. Sheu CW, Freese E (1973) Lipopolysaccharide layer protection of Gram negative bacteria against inhibition by long chain fatty acids. Journal of Bacteriology 115 (3): 869 875 .
23. Galbraith H, Miller TB (1973) Effect of long-chain fatty acids on bacterial respiration and amino acid uptake. Journal of Applied Microbiology 36 (4): 659 - 675. doi: 10.1111/j.13652672.1973.tb04151.x.

24. Burkhead KD, Schisler DA, Slininger PT (1995) Bioautography shows antibiotic production by soil bacterial isolates antagonistic to fungal dry rot of potatoes. Soil Biology and Biochemistry 27 (12): 1611 - 1616. doi: 10.1016/00380717(95)00095-V.

25. Thomshow LS, Bonsall RF, Weller D (2008) Detection of antibiotics produced by soil and rhizosphere microbes. In: Karlovsky P eds. Secondary metabolites in soil ecology soil biology. Heidelberg, Springer. pp $23-26$.

26. Hostettmann K (1999) Strategy for the biological and chemical evaluation of plant extracts. In Proceeding of International Conference on Biodiversity and Bioresources: Conservation and Utilization: 23 - 27 November 1997; Phuket.

27. Choma IM, Grzelak EM (2011) Review-Bioautography detection in thin-layer chromatography. Journal of Chromatography A 1218 (19): 2684 - 2691. doi: 10.1016/j.chroma.2010.12.069. 